Finansal Gelişme ve Ekonomik Büyüme Arasındaki Nedensellik İlişkisi: G7 Ülkeleri Örneği*

\title{
Causal Relationship Between Financial Development and Economic Growth: The Case of 67 Countries
}

\author{
Arş. Gör. İbrahim YAĞLI ${ }^{D} 1$, Dr. Öğr. Üyesi Ebru TOPCU (iD)2
}

\begin{abstract}
Öz
Finansal gelişme ile ekonomik büyüme arasındaki nedensellik ilişkisi son dönemin ilgi çeken konularındandır. Ancak yapılan çalışmalarda hem ilişkinin yönü hem de finansal gelişmeyi temsil eden göstergeler üzerinde bir görüş birliği bulunmamaktadır. Bu bağlamda çalışmanın temel amac1, 2005-2015 döneminde G7 ülkelerinde finansal gelişme ile ekonomik büyüme arasındaki nedensellik ilişkisinin incelenmesidir. $\mathrm{Bu}$ noktadan hareketle çalışmada finansal gelişme; derinlik, etkinlik ve yasal düzenlemeler olmak üzere üç farklı kategori altında incelenmiştir. Her bir kategoride finansal gelişmeyi temsil eden farklı değişkenler bulunmaktadır. Bu nedenle, Temel Bileşenler Analizi kullanılarak her bir başlık için ayrı birer endeks oluşturulmuştur. Panel Vektör Düzeltme Modeli sonuçları, uzun dönemde üç endeks ile ölçülen finansal gelişmeden ekonomik büyümeye doğru tek yönlü bir nedensellik ilişkisinin olduğunu ortaya çıkarmıştır. Bununla birlikte, kısa dönemde üç endeksten sadece etkinlik endeksi ile ekonomik büyüme arasında karşılıklı bir nedensellik ilişkisinin olduğu tespit edilmiştir. Sonuçlar bir bütün olarak değerlendirildiğinde, G7 ülkelerinde finansal gelişme ile ekonomik büyüme arasındaki ilişkinin finansal gelişmeden ekonomik büyümeye doğru olduğu, finansal piyasalarda yaşanan gelişmelerin ekonomik büyüme üzerindeki yansımalarının zaman aldığı söylenebilir.
\end{abstract}

Anahtar Kelimeler: Finansal gelişme, ekonomik büyüme, temel bileşenler analizi, panel nedensellik

Makale Türü: Araştırma

\begin{abstract}
The causal relationship between financial development and economic growth is one of the interesting topics in recent years. However, there is no consensus on the direction of the relationship and the indicators representing financial development. In this context, the main purpose of this study is to examine the causality between financial development and economic growth in the G7 countries during the period of 2005-2015. From this point of view, financial development is evaluated under three different categories; depth, efficiency and legal regulations. In each category, there exist different variables representing financial development. Therefore, a separate index is constructed for each main group using Principal Component Analysis. Panel Vector Correction Model results demonstrated that there is one-way causal relationship from financial development which is measured by three indices to economic growth. Nevertheless, it is ascertained that there is bi-directional causal relationship between only efficiency index out of three indices and economic growth in the short-term. All in all, it can be said that the direction of the relationship between financial development and economic growth is from financial development to economic growth for G7 countries and it takes time for the developments in the financial markets to reflect on economic growth.
\end{abstract}

Keywords: Financial development, economic growth, principal component analysis, panel causality

\footnotetext{
*Bu çalışmanın ilk hali 12.10.2017 tarihinde Konya'da düzenlenen I. Uluslararası Sosyal ve Ekonomik Araştırmalar Öğrenci Kongresi'nde sözlü bildiri olarak sunulmuştur.

${ }^{1}$ Nevşehir Hacı Bektaş Veli Üniversitesi, İ̈BF, ibrahimyagli@ nevsehir.edu.tr.

2 Nevsehir Hacı Bektaş Veli Üniversitesi, IİBF, ebruerdogan@nevsehir.edu.tr.

Atıf için (to cite): Yağlı, İ. ve Topcu, E. (2019). Finansal Gelişme ve Ekonomik Büyüme Arasındaki Nedensellik İlişkisi: G7 Ülkeleri Örneği. Afyon Kocatepe Üniversitesi Sosyal Bilimler Dergisi, 21(3), 888-898.
} 
Paper Type: Research

\section{Giriş}

Gerek gelişmiş gerekse gelişmekte olan ülkelerin gündemini meşgul eden önemli konuların başında ekonomik büyüme gelmektedir. Bu nedenle ekonomik büyümenin temel itici güçlerinin neler olduğu birçok araştırmacı tarafindan incelenmiştir. Finansal gelişmenin ekonomik büyümenin temel itici güçlerinden biri olarak ele alınmasının sebebi finansal sistemin üstlendiği fonksiyonlardan ileri gelmektedir. Finansal sistem fon arz edenler, fon talep edenler, aracılar, finansal araçlar ile düzenleyici ve denetleyici kuruluşlardan oluşan, finansal piyasayı da içine alan bir sistemdir. Finansal sistem, malların ve hizmetlerin değişimine aracılık etmek, tasarruf birikimi ve risk dağıtımına olanak vererek mülkiyeti tabana yaymak, zaman ve mekân ayarlaması yaparak kaynakların zaman içinde ve farklı coğrafi bölgeler arasında değişimini sağlamak, riskin yönetilmesini ve kontrolünü sağlamak, fiyat bilgisi oluşturmak, asimetrik bilgi sorununu çözmek gibi fonksiyonları yerine getirmektedir (Aras ve Müslümov, 2003). Levine (1997) ise finansal sistemin fonksiyonlarını; tasarrufları harekete geçirmek, kaynakları tahsis etmek, kurumsal kontrolü sağlamak, riski çeşitlendirmeye ve riskten korunmaya olanak tanımak şeklinde sıralamaktadır.

Bununla birlikte, finansal sistemin ekonomik büyümede oynadığ 1 role ilişkin çelişkili görüşler ortaya atılmıştır. Örneğin, Levine (1997) finansal fonksiyonların sermaye birikimi ve teknolojik gelişmeye yol açarak büyümeyi desteklediğini; Lucas (1988) finansal sistemin ekonomik büyümedeki rolünün abartıldığını ve finansal piyasadaki gelişmelerle reel büyüme arasında herhangi bir ilişki olmadığını; Demetriades ve Hussein (1996) finansal piyasalardaki gelişme ile ekonomik büyüme arasında karşıllklı bir etkileşim olduğunu; Robinson (1952) ise finansal gelişmenin ekonomik büyümenin bir sonucu olduğunu ileri sürmüştür. Bu görüşler 1şı̆̆ında ilgili literatürde, arz öncüllü görüş, talep takipli görüş, karşl1ıklı etkileşim görüşü ile finansal gelişme ile ekonomik büyüme arasında nedensel bir ilişkinin olmadığına ilişkin görüş olmak üzere dört farkl1 teorik görüş geliştirilmiştir (Apergis vd., 2007: 180).

Arz öncüllü görüşte, finansal sistemde yaşanan gelişmelerin ekonomik büyümeyi destekleyeceği ifade edilirken; talep takipli görüş finansal sistemlerin gelişmesinin reel ekonomideki aktörlerin - tasarruf sahibi ve yatırımcıların - finansal hizmetlere olan talebine bağlı olduğu üzerine kurulmuştur (Patrick, 1966: 174-176). Arz öncüllü görüşe göre, finansal sistem, piyasa aksaklıklarını azaltarak kaynakların tahsisindeki verimliliği arttırmakta ve ekonomik büyümeyi desteklemektedir (Demirgüç-Kunt, 2006: 1). Talep takipli görüşte ise ekonomik büyümeye paralel olarak artan finansal hizmet talebi finansal sistemin gelişmesine neden olmaktadır (Calderón ve Liu, 2003: 322). Finansal gelişme ile ekonomik büyüme arasındaki nedensellik ilişkisi ile ilgili olarak ortaya atılan diğer bir görüş ise karş1lıklı etkileşim görüşüdür. Arz öncüllü görüş ile talep takipli görüşün birleşimi olarak nitelendirilebilecek bu görüşte, finansal gelişmenin ekonomik büyümeyi, ekonomik büyümenin de finansal gelişmeyi desteklediği, diğer bir ifadeyle, etkinin karş1lıklı olduğu ileri sürülmektedir. Daha ayrıntılı olarak, finansal gelişme ile ekonomik büyüme arasındaki nedensellik ilişkisi aşamalı olarak incelenecek olursa, finansal gelişme ekonomik gelişmenin ilk aşamalarında reel sermaye oluşumunu teşvik etmektedir, ancak finansal ve ekonomik gelişme arttıkça, finansal gelişmenin ekonomik büyüme üzerindeki itici gücü azalmakta, talep takipli görüş baskın hale gelmektedir (Patrick, 1966:177). Son görüş ise finansal gelişme ile ekonomik büyüme arasında nedensellik ilişkisi olmadığı üzerine kurulmuştur.

İlgili literatür incelendiğinde bu görüşlerden, arz öncüllü ve talep takipli görüşlerin diğer iki görüşe kıyasla daha fazla benimsendiği görülmekle birlikte, bu durum finansal gelişme ile ekonomik büyüme arasındaki nedensellik ilişkisi ile ilgili olarak bir görüş birliği olmadığı gerçeğini değiştirmemektedir. Bu noktadan hareketle, çalışma ile ulaşılmak istenen amaç G7 ülkeleri (Almanya, ABD, Birleşik Krallık, Fransa, İtalya, Japonya ve Kanada) için finansal 
gelişme ile ekonomik büyüme arasında ilişki olup olmadığını, eğer böyle bir ilişki söz konusu ise ilişkinin yönünü tespit etmektir.

Çalı̧̧manın mevcut literatüre iki açıdan katkı sağlaması beklenmektedir: (i) Finansal gelişme ile ekonomik büyüme arasındaki ilişkiyi inceleyen çalışmalar daha çok gelişmekte olan ülkelere odaklanırken (Bk. Al-Yousif, 2002; Christopoulos ve Tsionas, 2004; Habibullah ve Eng, 2006; Abu-Bader ve Abu-Qarn, 2008; Hassan, Sanchez ve Yu, 2011; Kar, Nazlıoglu ve Ağır, 2014), gelişmiş ülkeleri ele alan çalışma sayısı oldukça sınırlı kalmıştır. Bu nedenle çalışmada gelişmiş ülkelerden oluşan G7 ülkeleri incelenerek, gelişmiş ülkelerde finansal gelişme ile ekonomik büyüme arasındaki ilişki ele alınacaktır. (ii) Literatürde yer alan çalışmalarda finansal gelişmişlik göstergesi olarak M2, finansal kurumlar tarafından özel sektöre verilen krediler, hisse senedi piyasası kapitalizasyonu gibi değişkenler kullanılmaktadır (Bk. Levine ve Zervos, 1998; Kar ve Pentecost, 2000; Calderon ve Liu, 2001; Bitterncourt, 2012). Finansal gelişme göstergesi olarak kullanılan bu değişkenler ne kapsamlı ne de tam olarak tatmin edicidir (Honohan, 2004:1). Çünkü finansal gelişme, finansal sistemlerin niceliğinde yaşanacak gelişmeler kadar niteliğinde yaşanacak gelişmeleri de kapsamaktadır. Buradan hareketle, çalışmada finansal gelişme göstergesi olarak finansal derinliğin yanı sıra finansal sistemin etkinliğini ve yatırımcıların korunması ile ilgili yasal düzenlemeleri de içeren değişkenler dikkate alınmıştır. Bu nedenle finansal piyasalarda kullanılan birbiriyle ilişki göstergeler temel bileşenler analizi yöntemiyle üç endeks altında toplanarak, finansal sistemde hangi başlık altında yaşanan gelişmelerin ekonomik büyüme üzerinde daha fazla etki yarattığ ortaya çıkarılmıştır. Dolayısıyla kapsamlı bir değişken seti ve kategorisi kullanılarak literatüre katkı sağlanması planlanmaktadır.

Çalışmanın geri kalanı aşağıdaki gibi organize edilmiştir. Bu bölümü takip eden birinci bölümde literatür taraması yer almaktadır. Üçüncü bölümde, kullanılan veri seti ve yöntem hakkında bilgi verilmiştir. Üçüncü bölümde analizler sonucunda elde edilen bulgular yer almaktadır. Dördüncü bölüm olan sonuç bölümde ise çalışmadan elde edilen sonuçlar ile politika önerilerine yer verilmiştir.

\section{Literatür Taraması}

Finansal gelişme ile ekonomik büyüme ilişkisi yeni bir konu olmayıp, anılan ilişki birçok ülke veya ülke grubu için ampirik olarak test edilmiştir. Bununla birlikte, finansal gelişme ile ekonomik büyüme arasındaki nedensellik ilişkisinin yönü ile ilgili bir fikir birliğine ulaşılamamıştır. Bazı çalışmalarda finansal gelişmenin ekonomik büyümeyi desteklediği sonucu elde edilirken (King ve Levine, 1993; Beck vd., 2000; Liang ve Jian-Zhou, 2006; Aslan ve Küçükaksoy, 2006; Altıntaş ve Ayrıçay, 2010; Karaca, 2012; Kandil, 2017); bazılarında ise ekonomik büyümenin finansal gelişmeyi desteklediği sonucu bulunmuştur (Kar ve Pentecast, 2000; Kandır vd., 2007; Zang ve Kim, 2007; Özcan ve Arı, 2011). Yine bazı çalışmalarda ilişkinin karşıllklı olduğu görülürken (Blackburn ve Hung, 1998; Al-Yousif, 2002; Öztürk, 2008; Kaya, 2014; Kar vd. 2014), bazılarında finansal gelişme ile ekonomik büyüme arasında bir ilişki olmadığı ortaya çıkarılmıştır (Chang, 2002; Anwar ve Sun, 2011).

Finansal gelişme ile ekonomik büyüme arasındaki nedensellik ilişkisine benzer şekilde, finansal gelişmişlik için kullanılan değişkenler üzerinde de bir uzlaşma yoktur. Bazı araştırmacılar finansal gelişmişliği ölçmek için endeks oluşturmayı tercih ederken (Adu vd. 2013; Menyah vd. 2014), bazıları finansal gelişmişliği bireysel göstergeler kullanarak ölçmüşlerdir (Kandır vd. 2007; Altıntaş ve Ayrıçay, 2010; Özcan ve Arı, 2011; Bayar vd. 2014; Cojocaru vd. 2016; Ono, 2017; Paun vd. 2019). Bununla birlikte, çoğu çalışmada finansal gelişmişliğin ölçülmesinde parasal büyüklükler, banka mevduatları, özel sektöre açılan krediler, payları borsada işlem gören şirketlerin toplam piyasa değeri gibi daha çok derinlik göstergesi sayılabilecek göstergelerin GSYH'ya oranı kullanılmıştır (Halıcıoğlu, 2007; Hassan, Sanchez ve Yu, 2011; Narayan ve Narayan, 2013). 
Yukarıda açıklandığı gibi finansal gelişme-ekonomik büyüme ilişkisini ölçmede kullanılan değişkenler ve elde edilen bulgular çeşitlilik göstermektedir. Bununla birlikte, gelişmiş ülkelerde anılan ilişkiyi ele alınan bazı çalışmalar aşağıdaki gibi özetlenebilir.

Lee (2005), Kanada'da VAR yöntemiyle finansal geliş̧me ile ekonomik büyüme arasındaki ilişkiyi ele almıştır. Elde edilen bulgular, finansal büyümeden ekonomik büyümeye doğru tek yönlü bir nedensellik ilişkisinin olduğunu ortaya koymuştur. Shan ve Jianhong (2006), 1978-2001 dönemini içeren verilerle Çin'de finansal gelişme ile ekonomik büyüme arasındaki nedensel ilişkiyi VAR yöntemiyle araştırmıştır. Ampirik bulgular, finansal gelişme ile ekonomik büyüme arasında çift yönlü bir nedensellik ilişkisi olduğunu ortaya koymuştur. Kemal vd. (2007), çok gelişmiş 19 ülkede finansal gelişme ile ekonomik büyüme arasındaki nedensellik ilişkişini incelemişlerdir. Çalışmadan elde edilen bulgular, değişkenler arasında herhangi bir nedensellik ilişkisinin olmadığını göstermiştir. Antonios (2010), Granger nedensellik analizini kullanarak Almanya'da finansal gelişmeden ekonomik büyümeye doğru tek yönlü bir ilişkinin varlığını kanıtlamıştır. Vektör Hata Düzeltme Modelini kullanarak Vazakidis ve Adamopoulos (2011), İngiltere'de 1965-2007 dönemine ait verileri kullanarak finansal gelişmeden ekonomik büyümeye doğru tek yönlü bir nedensellik ilişkisinin varlığını ispatlamıştır.

\section{Veri Seti ve Model}

Çalışmanın amacı, finansal gelişmenin ekonomik büyüme üzerindeki etkisinin G7 ülkelerinde analiz edilmesidir. Bu ilişki $2005-2015^{\text {a }}$ dönemini kapsayan veriler aracılığıyla incelenmiştir. Çalışmada finansal gelişmeyi temsil eden ölçütlerin neler olacağ 1 son derece önemli bir husustur. En basit şekilde finansal gelişme, finansal sistemi oluşturan unsurların finansal piyasa, finansal araçlar, aracılar, düzenleyici ve denetleyici kuruluşlar- gelişmesi şeklinde tanımlanabilir. Bir başka tanıma göre finansal gelişme, finansal sistemin hacminde ve yapısında meydana gelen olumlu değişimdir (Afşar, 2007: 190). Bununla birlikte, Abu-Bader ve Abu-Qarn (2008: 890) finansal gelişmeyi, finansal aracılık hizmetlerinin niceliğinde, kalitesinde ve etkinliğinde yaşanan gelişmeler süreci olarak tanımlamaktadır.

Bu bağlamda finansal gelişme derinlik, etkinlik ve yasal düzenlemeler olmak üzere üç farklı kategoride ele alınmıştır. Her bir kategori kendi içinde çeşitli finansal gelişme göstergelerinden oluşmaktadır. ${ }^{b}$ Temel Bileşenler Analizi yöntemi kullanılarak derinlik, etkinlik ve yasal düzenlemeler kategorilerini temsil eden üç farklı endeks oluşturulmuştur. Temel Bileşenler Analizi, çoklu veri analizlerinde kullanılan modern yöntemlerden biridir. Bir diğer ifadeyle, karmaşı veri setlerinden mikro veriler elde etmeye yarayan bir metottur. Bu analiz ile mevcut veriler birbiri ile ilişkili olmayan yeni verilere dönüştürülmektedir (Çoban ve Topcu, 2013: 83).

Çalışmada ekonomik büyüme, finansal gelişmenin yanı sıra kontrol değişkeni olarak adlandırılan emek ve sermayenin bir fonksiyonudur. Bu fonksiyon panel veri yönteminde cebirsel olarak aşağıdaki gibi ifade edilebilir:

$$
y_{i, t}=\beta_{0}+\beta_{1 i} k_{i t}+\beta_{2 i} l_{i t}+\beta_{3 i} g_{i t}+\varepsilon_{i t}
$$

\footnotetext{
a Yaşanan veri sıkıntısı nedeni ile analiz 2005-2015 dönemini kapsamaktadır.

${ }^{\mathrm{b}}$ Derinlik kategorisi, Mevduat Bankası Aktiflerinin GSYH'ya Oranı (\%); Ulusal Kredilerinin Özel Sektör Kredilerine Oranı (GSYH' nın \%); Sermaye Piyasası Kapitalizasyonunun GSYH'ya Oranı (\%); Sermaye Piyasasının Toplam İşlem Hacminin GSYH'ya oranı (\%); Dış Borçların GSYH'ya Oranı (\%); Mevduat Bankaları Tarafindan Özel Sektöre Verilen Kredilerin GSYH'ya Oranı (\%)" değişskenlerinden oluşmaktadır. Etkinlik kategorisi, Bankaların Faiz Dışı Gelirlerinin Toplam Gelire Oranı (\%); Bankaların Genel Giderlerinin Toplam Varlıklarına Oranı (\%); Aktif Banka Getiri Oranı (\%, vergi sonrası); Bankanın Özsermaye Getiri Oranı (\%, vergi sonrası); Banka Maliyetleri/ Gelir Oranı (\%); Boone Göstergesi; Hisse Senedi Piyasası Devir Hızı (\%)" değişkenlerinden oluşmaktadır. Yasal düzenlemeler kategorisi; "Azınlık Yatırımcıların Korunması - Yönetici Sorumluluk Endeksinin Kapsamı (0-10); Azınlık Yatırımcıların Korunması - Şeffaflık Endeksinin Kapsamı (0-10); Azınlık Yatırımcıların Korunması - Pay Sahiplerinin Görevi Kötüye Kullanmaktan Ötürü Yöneticilere Dava Açma Yetkisi (0-10); Kredi Alma - Yasal Haklar Endeksinin Etkinliği (0-10)" değişkenlerinden oluşmaktadır.
} 
Modelde, $y$ bağımsız değişken ekonomik büyümeyi temsil etmektedir ve Gayri Safi Yurtiçi Hasıla (2010 sabit fiyatlarıyla ABD Doları cinsinden) ile ölçülmektedir. Kontrol değişkenleri olan $k$ ve $l$ sirasıyla sermaye ve emeği temsil etmektedir. Bu değişkenler sirasıyla Gayri Sabit Sermaye Oluşumu (2010 sabit fiyatlarıyla ABD Doları cinsinden) ve toplam işgücü ile ölçülmektedir. Söz konusu veriler Dünya Bankası Dünya Kalkınma Göstergeleri veri tabanından elde edilmiştir. $f g$ terimi ise finansal gelişme değişkenini temsil etmektedir. $\mathrm{Bu}$ değişkenlere Küresel Finansal Kalkınma veri tabanından ulaşılmıştır. Finansal gelişme ise derinlik, etkinlik ve yasal düzenlemeler endeksleri ile ölçülmektedir. Burada $i$ indisi ülkeleri, $t$ indisi zaman periyodunu, $\beta_{0}$ terimi sabit terimi, $\epsilon$ terimi ise rassal hata terimini temsil etmektedir.

Modelde finansal gelişme derinlik, etkinlik ve yasal düzenlemeler olmak üzere üç farklı kategori ile ölçülmektedir. Bu nedenle çalışmada üç farklı model kurulmuştur:

$$
\begin{aligned}
& y_{i, t}=\beta_{0}+\beta_{1 i} k_{i t}+\beta_{2 i} l_{i t}+\beta_{3 i} d_{i t}+\varepsilon_{i t} \\
& y_{i, t}=\beta_{0}+\beta_{1 i} k_{i t}+\beta_{2 i} l_{i t}+\beta_{3 i} e_{i t}+\varepsilon_{i t} \\
& y_{i, t}=\beta_{0}+\beta_{1 i} k_{i t}+\beta_{2 i} l_{i t}+\beta_{3 i} d_{i t}+\varepsilon_{i t}
\end{aligned}
$$

(2) numaralı denklemde (Model 1) $d$ terimi derinlik değişkenini, (3) numaralı denklemde (Model 2) yer alan e terimi etkinlik değişkenini, (4) numaralı denklemde (Model 3) gösterilen $y d$ terimi ise yasal düzenlemeler değişkenini ifade etmektedir.

\section{Yöntem ve Bulgular}

\subsection{Birim Kök Testi}

Durağan serilerle yapılan analizler daha doğru ve tutarlı sonuçlar vermektedir. $\mathrm{Bu}$ nedenle analiz yapılmadan önce serilerin durağan olup olmadıklarının (birim kök içerip içermediklerinin) test edilmesi gerekmektedir. Panel veri tekniği ile yapılan analizlerde yaygın olarak kullanılan birim kök testleri Levin, Lin ve Chu (2002) ile Im, Peseran ve Shin (2003) birim kök testleridir. Bu çalışmada Im, Peseran ve Shin (IPS) birim kök testi kullanılmıştır. Bu testte serilerin birim kök içerdiği (durağan olmadığı) boş hipotezi, serilerin birim kök içermediği

\begin{tabular}{|c|c|c|}
\hline Değişken & Seviye & IPS \\
\hline \multirow{2}{*}{ d } & Düzey & 0.199 \\
\hline & I. fark & $-1.414^{*}$ \\
\hline \multirow[b]{2}{*}{$\mathrm{e}$} & Düzey & -0.32 \\
\hline & I. fark & $-2.460^{* * * *}$ \\
\hline \multirow[b]{2}{*}{ yd } & Düzey & 0.343 \\
\hline & I. fark & $-1.781^{* * *}$ \\
\hline \multirow{2}{*}{1} & Düzey & -0.212 \\
\hline & I. fark & $-2.069^{* *}$ \\
\hline \multirow{2}{*}{$\mathrm{k}$} & Düzey & -0.195 \\
\hline & I. fark & $-2.915^{* * * *}$ \\
\hline \multirow[b]{2}{*}{$\mathrm{y}$} & Düzey & -0.454 \\
\hline & I. fark & $-2.915^{* * * *}$ \\
\hline
\end{tabular}
(durağan olduğu) alternatif hipotezine karşı sınanmaktadır.

Tablo 1. IPS birim kök testi sonuçları

\subsection{Eşbütünleşme Analizi}

Birim kök testi ile serilerin birinci farklarında durağan olduklarının tespit edilmesinden sonra serilerin uzun dönemde birlikte hareket edip etmediklerinin tespit edilmesi mümkün 
olmaktadır. Bu noktada, Pedroni (1999) tarafindan geliştirilen ve modelde yer alan tüm değişkenlerin aynı seviyede durağan olduğu koşullarda kullanılabilecek eşbütünleşme testinden faydalanılmıştır.

Pedroni (1999), eşbütünleşme analizi için dört tanesi kesit-içi ve üç tanesi kesitleraras1 olmak üzere yedi test geliştirmiştir. Söz konusu bu yedi test ile "paneli oluşturan bütün yatay kesitler için eşbütünleşme ilişkisi yoktur" boş hipotezi "paneli oluşturan bütün yatay kesitler için eşbütünleşme ilişkisi vardır" alternatif hipotezine karşı sınanmaktadır.

Tablo 2. Eşbütünleșme testi sonuçları

\begin{tabular}{lllll}
\hline Boyut & Test & Model 1 & Model 2 & Model 3 \\
\hline \multirow{2}{*}{$\begin{array}{l}\text { Kesit-içi } \\
\text { eşbütünleşme } \\
\text { testleri }\end{array}$} & Panel-v & -0.398 & -0.265 & 0.294 \\
\cline { 2 - 5 } & Panel-rho & 1.564 & 1.408 & 0.872 \\
\cline { 2 - 5 } & Panel-pp & $-1.427^{*}$ & $-1.281^{*}$ & $-3.577^{* * *}$ \\
\cline { 2 - 5 } & Panel-adf & $-2.166^{* *}$ & $-1.645^{* *}$ & $-3.334^{* * *}$ \\
\hline \multirow{2}{*}{$\begin{array}{l}\text { Kesitleraras1 } \\
\text { eşbütünleşme } \\
\text { testleri }\end{array}$} & Grup-rho & 2.821 & 2.649 & 1.742 \\
\cline { 2 - 5 } & Grup-pp & $-3.395^{* * *}$ & $-4.851^{* * *}$ & $-6.623^{* * *}$ \\
\cline { 2 - 5 } & Grup-adf & $-4.655^{* * *}$ & $-3.075^{* * *}$ & $-4.256^{* * *}$ \\
\hline
\end{tabular}

Not: Gecikme sayısı 2 olarak belirlenmiştir. ${ }^{* * *},{ }^{* *}$ ve ${ }^{*}$ işaretleri sırasıyla $\% 1, \% 5$ ve $\% 10$ anlamlılık düzeylerini göstermektedir.

\subsection{Nedensellik Analizi}

Değişkenler arasında uzun dönemli bir ilişkinin tespit edilmesi, değişkenler arasındaki nedensellik ilişkisinin Panel Vektör Hata Düzeltme Modeli ile araştırılmasını gerekli kılar. Bu testte "değişkenler arasında nedensellik ilişkisi yoktur" boş hipotezi "değişkenler arasında nedensellik ilişkisi vardır” alternatif hipotezine karşı sınanmaktadır.

Tablo 3. Panel nedensellik analizi Model 1

\begin{tabular}{cccccc}
\hline & \multicolumn{3}{c}{ Model 1 } & \multicolumn{2}{c}{ Uzun dönem nedensellik } \\
\cline { 2 - 6 } Değişkenler & $\Delta \mathrm{y}$ & $\Delta \mathrm{k}$ & $\Delta \mathrm{l}$ & $\Delta \mathrm{d}$ & ECT \\
$\Delta \mathrm{y}$ & & 1.763 & $5.779^{\text {*** }}$ & 0.002 & $-0.050^{* * *}$ \\
$\Delta \mathrm{k}$ & 0.022 & & $15.989^{\text {*** }}$ & 0.583 & $-0.010^{* * *}$ \\
\hline$\Delta \mathrm{l}$ & $4.883^{* *}$ & $8.005^{* * *}$ & & $6.710^{* * *}$ & -0.017 \\
$\Delta \mathrm{d}$ & 0.034 & 0.220 & 0.037 & & -0.001 \\
\hline
\end{tabular}

\begin{tabular}{cccccc}
\hline \multicolumn{7}{c}{ Model 2 } \\
\hline \multirow{2}{*}{ Değişkenler } & $\Delta \mathrm{y}$ & $\Delta \mathrm{k}$ & $\Delta \mathrm{l}$ & $\Delta \mathrm{e}$ & Uzun dönem nedensellik \\
\cline { 2 - 5 }$\Delta \mathrm{y}$ & & 2.514 & $7.328^{* * *}$ & $5.166^{* *}$ & ECT \\
$\Delta \mathrm{k}$ & 0.025 & & $23.356^{* * *}$ & $6.444^{* *}$ & $-0.042^{* * *}$ \\
$\Delta \mathrm{l}$ & $3.530^{*}$ & $7.776^{* * *}$ & & $5.868^{* *}$ & $-002^{*}$ \\
$\Delta \mathrm{e}$ & $3.557^{*}$ & 1.646 & 0.635 & & $-0.002^{*}$ \\
\hline
\end{tabular}

Model 3

\begin{tabular}{cccccc}
\multicolumn{5}{c}{ Model 3 } & \multicolumn{2}{c}{ Uzun dönem nedensellik } \\
\hline & \multicolumn{3}{c}{ Kisa dönem nedensellik } & $\Delta \mathrm{l}$ & \multicolumn{1}{c}{ ECT } \\
Değişkenler & $\Delta \mathrm{y}$ & $\Delta \mathrm{k}$ & $16.146^{* * *}$ & 0.249 & $-0.042^{* * *}$ \\
$\Delta \mathrm{y}$ & & 4.153 & $26.744^{* * *}$ & 0.653 & $-0.152^{* * *}$ \\
$\Delta \mathrm{k}$ & 1.230 & & & 1.192 & $-0.019^{* * *}$ \\
$\Delta \mathrm{l}$ & $29.805^{* * *}$ & $41.651^{* * *}$ & & -0.002 \\
$\Delta \mathrm{yd}$ & 0.0247 & 0.021 & 0.412 & & \\
\hline
\end{tabular}

Not: Dikey sütundaki değişkenler bağımlı, yatay sütundaki değişkenler ise bağımsız değişkenlerdir. ECT değerleri hata düzeltme terimi katsayılarıdır. ${ }_{* * *}^{* *}$ ve ${ }^{*}$ işaretleri sirasılyla $\% 1, \% 5$ ve $\% 10$ anlamlılik düzeylerini göstermektedir. 
Tablo 3, Panel Vektör Hata Düzeltme testinden elde edilen sonuçları göstermektedir. Analizden elde edilen bulgulara göre, kısa dönemde derinlik ile ekonomik büyüme arasında herhangi bir nedensel ilişki yoktur. Uzun dönemde ise derinlikten ekonomik büyümeye doğru tek yönlü bir nedensellik ilişkisi söz konusudur. Model 2'ye ait analiz sonuçları incelendiğinde, hem kısa hem de uzun dönemde etkinlikten büyümeye doğru tek yönlü bir nedensellik ilişkisi olduğu yönünde bir bulgu elde edilmiştir. Ayrıca kısa dönemde etkinlikten büyümeye doğru da tek yönlü bir nedensellik ilişkisi tespit edilmiştir. Diğer bir ifadeyle, kısa dönemde ekonomik büyüme ile etkinlik arasında çift yönlü bir nedensellik ilişkisi bulunmaktadır. Model 3'e ait analiz sonuçları ise, kısa dönemde ekonomik büyüme ve yasal düzenlemeler arasında herhangi bir ilişki olmadığı bulgusunu ortaya koymuştur. Uzun dönemde ise yasal düzenlemelerden ekonomik büyümeye doğru tek yönlü bir nedensellik ilişkisi tespit edilmiştir.

Kontrol değişkenleri açısından nedensellik analizi ele alındığında, her üç modelde de hem kısa hem de uzun dönemde emek ve büyüme arasında çift yönlü bir nedensellik ilişkisi bulunduğu gözlemlenmiştir. Her üç modelde de, kısa dönemde sermaye ve büyüme arasında herhangi bir nedensellik ilişkisi tespit edilemezken, uzun dönemde sermayeden büyümeye doğru tek yönlü bir nedensellik ilişkisi bulgusuna ulaşılmıştır.

\section{Sonuç ve Öneriler}

Ekonomik büyüme, hem gelişmiş hem de gelişmekte olan ülkelerin gündemindeki önemli konulardan biridir. Finansal gelişme üstlendiği fonksiyonlar nedeniyle ekonomik büyümenin itici güçlerinden biri olarak ele alınmaktadır. Buna bağlı olarak finansal gelişme ile ekonomik büyüme arasındaki nedensellik ilişkisi birçok çalışmada incelenmiştir. Bununla birlikte, anılan ilişki daha çok gelişmekte olan ülkeler için araştırılmıştır. Çalışma ile literatürdeki bu boşluğun doldurulması, gelişmiş ülkelerde finansal gelişme - ekonomik büyüme ilişkisine yönelik çıkarımlar yapılması amaçlanmaktadır. Bu amaç doğrultusunda Almanya, ABD, Birleşik Krallık, Fransa, İtalya, Japonya ve Kanada'dan oluşan G7 ülkelerinde finansal gelişme ve ekonomik büyüme arasındaki ilişkinin 2005-2015 dönemi için araştırılmıştır. Ampirik literatürde finansal gelişmeyi ölçmek amacıyla çok sayıda farklı gösterge kullanılmaktadır. Bu çalışmada finansal gelişme, finansal piyasalarda etkinlik, derinlik ve yasal düzenlemeleri ölçen çeşitli göstergelerden elde edilen üç farklı endeks ile ölçülmüştür. $\mathrm{Bu}$ endeksleri elde etmek amacıyla Temel Bileşenler Analizi yönteminden yararlanılmıştır.

Çalışmada değişkenlerin birinci farklarında durağan oldukları tespit edildikten sonra, Pedroni Eşbütünleşme Testi ile seriler arasındaki uzun dönemli ilişki araştırılmıştır. Elde edilen bulgular, modelde yer alan seriler arasında uzun dönemli bir ilişki olduğunu ortaya koymuştur. $\mathrm{Bu}$ durum değişkenler arasındaki nedensellik ilişkisinin Panel Vektör Düzeltme Modeli ile araştırılmasına olanak tanımıştır.

Panel Vektör Düzeltme Modeli sonuçları, finansal gelişmişlik düzeyinin derinlik endeksi ile ölçüldügü Model 1'de kısa dönemde derinlik ile ekonomik büyüme arasında herhangi bir ilişki olmadığını göstermiştir. Bu bulgu, 19 yüksek gelirli gelişmiş ülkede finansal gelişme ile ekonomik büyüme arasında herhangi bir nedensel ilişki tespit edemeyen Kemal vd. (2007)'in çalışmasıyla paralellik göstermektedir. Uzun dönemde ise derinlikten ekonomik büyümeye doğru tek yönlü bir nedensellik ilişkisi bulgusuna ulaşılmıştır. Diğer bir ifadeyle, finansal piyasaların hacim olarak genişlemesi (M2'in artması, banka mevduatlarının artması gibi) kısa dönemde ekonomi üzerinde bir etki yaratmazken, uzun dönemde hacimdeki bu genişleme ekonomik büyümeyi desteklemektedir.

Finansal gelişmenin etkinlik endeksi ile ölçüldüğü Model 2 ile ilgili nedensellik analizi sonuçları, kısa dönemde etkinlik ile ekonomik büyüme arasında çift yönlü bir nedensellik ilişkisini ortaya koymuştur. Yani, G7 ülkelerinde kısa dönemde finansal piyasalarda etkinliğin artmas1 ekonomik büyümeyi; ekonomik büyümenin artmas1 ise finansal piyasalardaki etkinliği arttırmaktadır. Diğer bir deyişle, kısa dönemde karşılıklı bağımlılık görüşü geçerlidir. Bu bulgu, 
Çin'de söz konusu ilişkiyi inceleyen Shan ve Jianhong (2006)'un çalışmasıyla tutarlıdır. Uzun dönemde ise etkinlikten büyümeye doğru tek yönlü bir nedensellik ilişkisi söz konusudur.

Finansal gelişmenin yasal düzenlemeler endeksi ile ölçüldüğü Model 3'de ise, kısa dönemde yasal düzenlemeler ile ekonomik büyüme arasında herhangi bir nedensel ilişki tespit edilemezken, uzun dönemde yasal düzenlemelerden ekonomik büyümeye doğru tek yönlü bir nedensellik ilişkisi tespit edilmiştir. Söz konusu bulgu, uzun dönemde arz öncüllü görüşün geçerliliğini desteklemektedir. Bu bağlamda, G7 ülkelerinde asimetrik bilgi problemlerini azaltacak, hissedarların haklarını koruyacak düzenlemelerdeki gelişmelerin yatırımcıların piyasaya olan güvenini arttıracağı, buna bağlı olarak birikimlerin yatırıma dönüşerek uzun dönemde ekonomik büyümenin yakalanacağı söylenebilir.

Sonuç olarak gelişmiş yedi ülkenin oluşturduğu G7 ülke topluluğunda, finansal gelişme ile ekonomik büyüme arasındaki ilişki araştırılırken finansal gelişme ölçütlerinden sadece etkinlik ile ekonomik büyüme arasında kısa dönemde bir nedensellik ilişkisi olduğu tespit edilmiştir. Uzun dönemde ise üç finansal gelişme endeksinden de ekonomik büyümeye doğru tek yönlü bir nedensellik ilişkisinin varlığı ispatlanmıştır. Diğer bir ifadeyle, uzun dönemde arz öncüllü görüş desteklenmektedir. Bu sonuçlar, King ve Levine (1993), Lee (2005); Antonios (2010) ve Vazakidis ve Adamopoulos (2011)'ın sonuçları ile paralellik göstermektedir.

$\mathrm{Bu}$ sonuçlardan hareketle, finansal piyasalarda hacim yönünden yaşanacak gelişmelerin yanı sıra, finansal piyasaların etkinliğini arttıracak gelişmeler ekonomik büyümeyi hem kısa dönemde hem de uzun dönemde olumlu yönde etkileyecektir. Dolayısıyla, finansal sistemin bir parçası olan denetleyici ve düzenleyici kurumların finansal sistemde hayati bir rolü bulunmaktadır ve söz konusu kurumların bu farkındalıkla faaliyette bulunmaları ekonomik büyümeyi beraberinde getirecektir.

Çalışmada endekslerin hesaplanmasında kullanılan değişkenlere ilişkin yeterli veriye erişilememesi sebebiyle kısıtlı bir periyodu içeren verilerle analiz yapılmıştır. Bununla birlikte, çalışmanın örneklemi G7 ülkeleri ile sınırlandırılmıştır. Söz konusu kısıtlardan yola çıkarak benzer konuda çalışacak araştırmacılar için çeşitli öneriler sunulabilir. Bu bağlamda, finansal gelişmenin ölçülmesinde kullanılan endeks kategorileri genişletilerek gelişmiş ve gelişmekte olan ülke kıyaslaması yapmak çalışmayı daha ileri bir noktaya taşıyacaktır. Ayrıca daha geniş bir zaman periyodunu içeren veri seti ile çalışmak daha kapsamlı bir değerlendirme şansı sunacaktır.

\section{Kaynakça}

Abu-Bader, S. ve Abu-Qarn, A. S. (2008). Financial Development and Economic Growth: The Egyptian Experience. Journal of Policy Modeling, 30(5): 887-898.

Adu, G., Marbuah, G. ve Mensah, J. T. (2013). Financial Development and Economic Growth in Ghana: Does the Measure of Financial Development Matter?. Review of Development Finance, 3(4): 192-203.

Afşar, A. (2007). Finansal Gelişme ile Ekonomik Büyüme Arasındaki İlişki. Muhasebe Finansman Dergisi, 36: 188-198.

Altıntaş, H. ve Ayrıçay, Y. (2010). Türkiye'de Finansal Gelişme ve Ekonomik Büyüme İlişkisinin Sınır Testi Yaklaşımıyla Analizi: 1987-2007, Anadolu University Journal of Social Science, 10(2): 71-98.

Al-Yousif, Y. K. (2002). Financial Development and Economic Growth: Another Look at the Evidence from Developing Countries. Review of Financial Economics, 11(2): 131-150.

Antonios, A. (2010). Stock Market and Economic Growth: An Empirical Analysis for Germany. Business and Economics Journal, 2010(1):1-12. 
Anwar, S. ve Sun, S. (2011). Financial Development, Foreign Investment and Economic Growth in Malaysia. Journal of Asian Economics, 22(4): 335-342.

Apergis, N., Filippidis, I. ve Economidou, C. (2007). Financial Deepening and Economic Growth Linkages: A Panel Data Analysis. Review of World Economics, 143(1): 179-198.

Aras, G. ve Müslümov A. (2003). Sermaye Piyasalarının Gelişmesinde Kurumsal Yatırımcıların Rolü: OECD Ülkeleri ve Türkiye, İstanbul: Kurumsal Yatırımcı Yönetici Derneği.

Aslan, Ö. ve Küçükaksoy, İ. (2006). Finansal Gelişme ve Ekonomik Büyüme İlişkisi: Türkiye Ekonomisi Üzerine Ekonometrik Bir Uygulama. Ekonometri ve İstatistik e-Dergisi, 4: 25-38.

Bayar, Y., Kaya, A. ve Yıldırım, M. (2014). Effects of Stock Market Development on Economic Growth: Evidence from Turkey. International Journal of Financial Research, 5(1): 93-100.

Beck, T. Levine, R. ve Loayza, N. (2000). Finance and the Sources of Growth. Journal of Financial Economics, 58(1-2): 261-300.

Bittencourt, M. (2012). Financial Development and Economic Growth In Latin America: Is Schumpeter Right?. Journal of Policy Modeling, 34(3): 341-355.

Blackburn, K. ve Hung, V. T. (1998). A Theory of Growth, Financial Development and Trade. Economica, 65(257): 107-124.

Calderón, C. ve Liu, L. (2003). The Direction of Causality between Financial Development and Economic Growth. Journal of Development Economics, 72(1): 321-334.

Chang, T. (2002). Financial Development and Economic Growth in Mainland China: A Note on Testing Demand-Following or Supply-Leading Hypothesis. Applied Economics Letters, 9(13): 869-873.

Christopoulos, D. K. ve Tsionas, E. G. (2004). Financial Development and Economic Growth: Evidence from Panel Unit Root and Cointegration Tests. Journal of Development Economics, 73(1): 55-74.

Coban, S. ve Topcu, M. (2013). The Nexus between Financial Development and Energy Consumption in the EU: A Dynamic Panel Data Analysis. Energy Economics, 39: 81-88.

Cojocaru, L. F., Evangelos M., Hoffman, S. D. ve Miller, J. B. (2016). Financial System Development and Economic Growth in Transition Economies: New empirical Evidence from the CEE and CIS Countries. Emerging Markets Finance and Trade, 52(1): 223-236.

Demetriades, P. O. ve Hussein, K. A. (1996). Does Financial Development Cause Economic Growth? Time-Series Evidence from 16 Countries. Journal of Development Economics, 51(2): 387-411.

Demirguc-Kunt, A. (2006). Finance and Economic Development: Policy Choices for Developing Countries, Washington DC: World Ban.

Habibullah, M. S. ve Eng, Y. (2006). Does Financial Development Cause Economic Growth? A Panel Data Dynamic Analysis For The Asian Developing Countries. Journal of the Asia Pacific Economy, 11(4): 377-393.

Halicioglu, F. (2007). The Financial Development and Economic Growth Nexus for Turkey (No. 06/2007). EERI Research Paper Series.

Hassan, M. K., Sanchez, B. ve Yu, J. (2011). Financial Development and Economic Growth: New Evidence from Panel Data. The Quarterly Review of Economics and Finance, 51(1): 88-104. 
Honohan, P. (2004). Financial Development, Growth And Poverty: How Close Are The Links?, In Financial Development and Economic Growth (Ed. C. A. E. Goodhart), London: Palgrave Macmillan.

Im K. S., Pesaran M. H. ve Shin Y. (2003). Testing for Unit Roots in Heterogeneous Panels. Journal of Econometrics, 115(1): 53-74.

Kandil, M., Shahbaz, M., Mahalik, M. ve Nguyen, D. (2017). The Drivers of Economic Growth in China and India: Globalization or Financial Development?. International Journal of Development Issues, 16(1): 54-84.

Kandır, S. Y., İskenderoğlu, Ö. ve Önal, Y. B. (2007). Gelişme ve Ekonomik Büyüme Arasındaki İlişskinin Araştırılması, Çukurova Üniversitesi Sosyal Bilimler Enstitüsü Dergisi, 16(2): 311-326.

Kar, M., Pentecost, E. J. (2000). Financial Development and Economic Growth in Turkey: Further Evidence on the Causality Issue. Centre for International, Financial and Economics Research, Department of Economics (Loughborough University), Economic Research Paper No. 00/27.

Kar, M., Nazlığlu, Ş. ve Ağır, H. (2014). Trade Openness, Financial Development and Economic Growth in Turkey: Linear and Nonlinear Causality Analysis. Journal of BRSA Banking \& Financial Markets, 8(1): 63-86.

Karaca, O. (2012). Finansal Gelişme ve Ekonomik Büyüme: Türkiye İçin Bir Nedensellik Analizi. Journal of BRSA Banking \& Financial Markets, 6(2): 85-111.

Kaya, A. (2014). Menkul Kiymet Piyasaları Ekonomik Büyümenin Bir Dinamiği Midir? Gelişmiş ve Gelişmekte Olan Ülkelere Yönelik Panel Veri Analizi. Atatürk Üniversitesi İktisadi ve İdari Bilimler Dergisi, 28(4): 285-306.

Kemal, A. R., Qayyum, A. ve Hanif, M. N. (2007). Financial Development and Economic Growth: Evidence from a Heterogeneous Panel of High Income Countries. The Lahore Journal of Economics, 12(1): 1-34.

King, R. G. ve Levine, R. (1993). Finance and Growth: Schumpeter Might be Right. Quarterly Journal of Economics, 108(3): 717-738.

Lee, J. (2005). Financial Intermediation and Economic Growth Evidence from Canada. New York: Eastern Economics Association.

Levin, A., Lin, C. ve Chu, C. J. (2002). Unit Root Tests in Panel Data: Asymptotic and Finitesample Properties. Journal of Econometrics, 108(1): 1-24.

Levine, R. ve Zervos, S. (1998). Stock Markets, Banks, and Economic Growth. American Economic Review, 88(3): 537-558.

Levine, R. (1997). Financial Development and Economic Growth: Views and Agenda. Journal of Economic Literature, 35(2): 688-726.

Liang, Q. ve Jian-Zhou, T. (2006). Financial Development and Economic Growth: Evidence from China. China Economic Review, 17(4): 395-411.

Lucas, R. E. (1988). On The Mechanics of Economic Development. Journal of Monetary Economics, 22(1): 3-42.

Menyah, K., Nazlıŏlu, S. ve Wolde-Rufael, Y. (2014). Financial Development, Trade Openness and Economic Growth in African Countries: New Insights from a Panel Causality Approach. Economic Modelling, 37: 386-394. 
Narayan, P. K. ve Narayan, S. (2013). The Short-Run Relationship Between The Financial System And Economic Growth: New Evidence From Regional Panels. International Review of Financial Analysis, 29: 70-78.

Ona, S. (2017). Financial development and economic growth nexus in Russia. Russian Journal of Economics, 3(3): 321-332.

Öztürk, İ. (2008). Financial Development and Economic Growth: Evidence from Turkey. Applied Econometrics and International Development, 8(1): 85-98.

Özcan, B. ve Arı, A. (2011). Finansal Gelisme ve Ekonomik Büyüme Arasındaki İlişkinin Ampirik Bir Analizi: Türkiye Örneği. Business and Economics Research Journal, 2(1): 121142.

Patrick, H. T. (1966). Financial Development and Economic Growth in Underdeveloped Countries. Economic Development and Cultural Change, 14(2): 174-189.

Paun, C. V., Musetescu, R. D., Topan, V. M. ve Danuletiu, D. C. (2019). The Impact of Financial Sector Development and Sophistication on Sustainable Economic Growth. Sustainability, 11, 1713.

Pedroni, P. (1999). Critical Values for Cointegration Tests in Heterogeneous Panels with Multiple Regressors. Oxford Bulletin of Economics and Statistics, 61(1): 653-670.

Robinson, J. (1952). The Rate of Interest and Other Essays, İçinde: The Generalization of the General Theory, London: MacMillan

Shan, J. ve Jianhong, Q. (2006). Does Financial Development 'Lead' Economic Growth? The Case of China. Annals of Economics and Finance, 1: 197-216.

Zang, H. ve Kim, Y. C. (2007). Does Financial Development Precede Growth? Robinson and Lucas Might Be Right. Applied Economics Letters, 14(1): 15-19.

Vazakidis, A. ve Adamopoulos, A. (2011). Financial Development and Economic Growth: An Empirical Analysis for the UK. European Research Studies Journal, 14(2): 135-148. 